\title{
Research
}

\section{Maternal depression and primary healthcare use for children:}

\author{
a population-based cohort study in Denmark
}

\begin{abstract}
Background

Depression is a common mental illness

worldwide. The offspring of a mother with depression has higher risk of developing mental and physical illness.
\end{abstract}

\section{Aim}

This study aimed to investigate the association between the timing of maternal depression and the use of primary health care for the offspring

\section{Design and setting}

A population-based birth cohort study in Danish primary care using Danish national registers.

\section{Method}

All Danish children born between 1 January 2000 and 31 December 2013 ( $n=869140$ children) were included in the study. The primary outcome was number and type of annual contacts with the GP. The secondary outcome was specific services used by the GP to assess inflammatory and infectious disease in the children. Exposure was maternal depression of four categories: non-depressed, recent, previous, and past depression. The association was expressed as adjusted incidence rate ratios (IRR) with 95\% confidence intervals (CI).

\section{Results}

Maternal depression was associated with a higher use of primary health care for al three categories of depression. The strongest association was found for children of a mother with recent depression; they had 16\% more contacts than children of a non-depressed mother ladjusted IRR $=1.16,95 \% \mathrm{Cl}=1.15$ to 1.17), and $19-24 \%$ more positive infectiousrelated tests were found in this group.

\section{Conclusion}

Exposure to maternal depression was associated with a significantly higher use of primary health care for the offspring for all exposure categories. These findings reveal that healthcare use is higher for the offspring exposed to maternal depression, even several years after expected remission. The higher ratio of positive tests indicates that exposed children are ill with infectious disease more often.

\section{Keywords}

child; depressive disorder; general practice; mothers; primary health care.

\section{INTRODUCTION}

Depression is one of the most frequent mental disorders. The lifetime prevalence rates range from $3 \%$ in Japan to $18 \%$ in the US, but they range from $8-12 \%$ in most countries. ${ }^{1,2}$ Mental illnesses have high personal, social, and financial costs. $^{3}$ Females have twice the risk of developing depression than males. ${ }^{2,4,5}$ The risk of developing mental illness increases significantly during the perinatal period for which depression rates of $20 \%$ have been reported. ${ }^{6-9}$

Maternal mental illness has been linked to a multitude of negative effects in motheroffspring interactions, including insecure attachment and insensitive parenting behaviour. ${ }^{10}$ The offspring is also at risk of psychological and physiological problems. The psychological problems include higher risk of psychiatric disorders and behavioural problems in childhood, ${ }^{11,12}$ and maternal depression has also been identified as a strong predictor for depression in later childhood. ${ }^{13}$ The physiological problems of maternal depression include increased risk of asthma in later childhood in children of mothers with a history of asthma; ${ }^{14}$ higher risk of gastrointestinal and respiratory infections in early childhood:15 increased risk of wheezing in infancy ${ }^{16}$ higher hazard of febrile illness in the first 2 years of life; ${ }^{17}$ and more diarrhoeal episodes in infancy. ${ }^{18}$

Research in the field of primary

BK Lyngsøe, MD, PhD student, Research Unit for General Practice; D Rytter, MSc, associate professor, Department of Public Health:

T Munk-Olsen, MSc, senior researcher, National Centre for Register-Based Research, Department of Economics and Business; $\mathrm{CH}$ Vestergaard, MD, Cand.scient.math, professor, Research Unit for General Practice; KS Christensen, MD, professor, Research Unit for General Practice; BH Bech, MD associate professor, Research Unit for General Practice, Aarhus University, Aarhus, Denmark. healthcare use for children of mothers with depression has yielded contradictory results. Some studies have found maternal depression or anxiety to be associated with increased use of primary health care for the offspring, ${ }^{19-22}$ whereas others have found only vague associations or no association. ${ }^{23,24}$ The majority of the existing literature investigates maternal depression during pregnancy or in the first year postpartum.

To address gaps in the existing knowledge, this research aimed to study the association between maternal depression and different types of contacts with primary health care regarding the offspring, and to explore the timing of maternal depression more extensively than previously seen. The researchers included out-of-hours contacts and supplementary services that indicated infectious disease to investigate the extent of acute illness in children exposed to maternal depression. To the researchers' knowledge, no previous studies have explored previous or past depression as exposure beyond the scope of the pregnancy, and no studies have investigated supplementary services provided by the GP

\section{METHOD}

\section{Setting}

Approximately $98 \%$ of the Danish population is listed with a GP. The GP serves as a gatekeeper to secondary care and handles

\section{Address for correspondence}

Bente K Lyngsøe, Research Unit for General Practice, Aarhus University, Bartholins Allé 2 . 8000 Aarhus C, Denmark

Email: bkllaph.au.dk

Submitted: 23 May 2018: Editor's response: 18 June 2018: final acceptance: 8 July 2018. (CBritish Journal of General Practice

This is the full-length article (published online 18 Dec 2018) of an abridged version published in print. Cite this version as: $\mathbf{B r} \mathbf{J}$ Gen Pract 2018; DOI: https://doi.org/10.3399/bjgp18X700733 


\section{How this fits in}

Depression in mothers has been linked to increased illness and excess use of health care in the offspring. This study confirms this and finds also that the association remains statistically significant for several years after treatment has ended. To reduce negative long-term effects of maternal depression in the offspring, interventions targeting pregnant females and mothers with depression should be considered in the planning of healthcare services.

most acute non-life-threatening illnesses, ${ }^{25}$ including diagnosis and management of most depressive disorders. ${ }^{26}$ The services are funded by the Danish tax system and are free of charge for the patients.

\section{Study design and population}

A population-based cohort study was conducted. All Danish citizens are assigned a unique personal identification number (PIN) at birth or immigration. This PIN can be used to link information in the Danish registers at a personal level.

The study population consisted of all children live-born in Denmark in the period 1 January 2000 to 31 December 2013 ( $n=869$ 140) and their mothers $(n=525$ 881). The children were identified in the Danish National Patient Register and linked to their mother through the Danish Civil Registration System. ${ }^{27,28}$ Children or mothers who died, disappeared, or emigrated during followup were censored from the analyses at the date of departure $(n=21010)$. The children were followed until their sixth birthday or 31 December 2013, whichever came first.

\section{Exposure: maternal depression}

When a female fulfilled any of the criteria for depression (Box 1) for the first time, she was categorised under 'recent depression' in the following 6 months. Thereafter, she was categorised under 'previous depression'. The previous category lasted from 6 months to at least 5 years after debut of depression. In case of a new admittances/outpatient contact/reimbursement, the previous period was prolonged by 6 months. Thus, at least 5 years after debut of depression, and 6 months since last fulfilment of the criteria, the female was categorised under 'past depression'. Once categorised under past depression, new fulfilment of the criteria would lead to reinclusion in the recent depression category. The reference group 'no depression' consisted of mothers who had yet to meet any of the criteria during follow-up.

Information on exposure measurements was obtained for the period 1994 to 2015 from the Register of Medicinal Product Statistics $^{29}$ and the Danish Psychiatric Central Research Register. ${ }^{30,31}$

\section{Outcome: children's contacts with GP}

Information on outcome was obtained from the Danish National Health Insurance Service Register, which contains information on services provided by GPs. ${ }^{32}$ Outcome was a summed measure of services during 1 year of the child's life ( $0-1$ years of age, $1-2$ years of age, and so on). Routine childcare visits and contacts

\section{Box 1. Criteria for exposure and description of exposure groups}

\begin{tabular}{lll} 
Exposure measures & \multicolumn{1}{c}{ Specifications } & Criteria required for depression \\
\hline Antidepressant medications & ATC codes & N06AB03, N06AB04, N06AB05, N06AB06, N06AB08, N06AB10, N06AF01, \\
& N06AG02, N06AX03, N06AX06, N06AX11, N06AX16, N06AX21, N06AX22 & contacts to a hospital within 6 months \\
\hline Admission to a hospital & Main diagnosis of depression according to the ICD-10 classification & $\geq 1$ admission to a hospital \\
& F32.0, F32.1, F32.2, F32.3, F32.8, F32.9, F33.0, F33.1, F33.2, F33.3, & $\geq 2$ prescriptions reimbursed or outpatient \\
\hline Outpatient contact to a hospital & Main diagnosis of depression according to the ICD-10 classification & contacts to a hospital within 6 months \\
\hline
\end{tabular}

\section{Categories of depression}

Recent depression: a woman was categorised under 'recent depression' from the date she met any of the three criteria for the first time. Previous depression: after 6 months, the woman was categorised under 'previous depression' for at least the following 54 months. Past depression: a woman was categorised under 'past depression' after at least 60 months from debut (of depression). No depression: a woman was categorised under 'no depression' if she had yet to meet any of the criteria. These were the reference group. 
due to vaccination were excluded. The primary outcome of interest was the type and total number of annual contacts with any GP. The total number of GP contacts per year included: daytime visits, daytime phone consultations, email consultations, out-of-hours visits, and out-of-hours phone consultations. The secondary outcome of interestwas specific supplementary services related to physical health examinations. Supplementary services provided by the GP because of an indication of inflammatory or infectious disease included: urinary sticks, streptococcal throat tests, capillary C-reactive protein (CRP) tests, spirometry, and tympanometry. As the registries do not include information on the results of the services, the first three supplementary tests were defined as positive if followed by reimbursement of antibiotics (Anatomical Therapeutic Chemical Classification [ACT] code J01) within a week of the performed test. This method has been previously used in research based on information from the Danish Register of Medicinal Product Statistics. ${ }^{33}$

\section{Covariates}

Time-dependent covariates were handled dynamically to allow for changes during follow-up. These dynamic covariates included maternal income (four groups), education level (four groups), and civil status (five groups); this information was obtained from Statistics Denmark. ${ }^{34}$ Information on paternal depression, which was defined by the same criteria as maternal depression (four groups), was obtained from the Danish Psychiatric Central Research Register. Maternal and paternal mental comorbidities, including drug use, alcoholism, eating disorders, schizophrenia, and dementia, and bipolar disorder as a dichotomous variable (any/none), were identified by an algorithm developed by Prior et al..$^{35}$

Time-independent covariates could not change during follow-up; these included: parity (indicators capped at 4), sex of the child, maternal age at birth (continuous), and gestational age (three groups). This information was obtained from the Danish Civil Registration System ${ }^{27}$ and the Danish National Patient Register. ${ }^{36}$

\section{Statistical analysis}

All analyses were performed using Stata (version 13), and significance level was defined by a $P$-value of $<0.05$. The total inclusion time, referred to as risk time, for each child was split into smaller periods according to changes in exposure or in any of the dynamic covariates. Each of these periods spanned a certain number of days. Within each timespan, the number of outcomes was counted and modelled by negative binomial regression to account for the length of each period, that is, number of risk days accrued in each period.

To accommodate the assumption of independence between within-child measurements, cluster robust variance (sandwich) estimation was applied. It was applied at mother-level to account for dependence from multiparity as well.

Results were aggregated for exposure and age of the child, and these are presented as adjusted incidence rate ratios (IRR) with 95\% confidence intervals $(\mathrm{Cl})$ and $P$-values.

A previous study by the present researchers found that children of mothers with depression missed the scheduled routine childcare visits more frequently. ${ }^{37}$ Therefore, a sub-analysis was performed to explore whether non-compliance with routine childcare modified the association between maternal depression and the use of health care for the offspring. Compliance was defined as attendance to each of the seven scheduled childcare visits within a certain timeframe. Because the children in the present study population had different ages at the end of follow-up, a sub-analysis that only included children born in the period 2000-2007 was performed.

\section{RESULTS}

At the time of childbirth, mothers with depression more often had a shorter education and a lower income. They were more often unmarried or divorced, and they were more likely to suffer from other mental comorbidities. Furthermore, children of mothers with depression were more often born preterm (Table 1).

Within each year of follow-up, children of mothers with depression had more contacts with the GP than children of mothers without depression. This association persisted through all types of contacts. The researchers found the highest number of contacts for children of mothers with recent depression; this group had the highest values for all types of contact, except for daytime telephone consultations. Exposure to maternal depression had the highest impact on healthcare use in the early years of a child's life (Figure 1).

Children of mothers with recent depression had $16 \%$ more total contacts during the first 6 years of life compared with children of mothers without depression, $\mid \mathrm{RR}=1.16,95 \% \mathrm{Cl}=1.15$ to 1.17 (Table 2). The average number of contacts in unexposed children was 37.9 
Table 1. Characteristics of maternal covariates measured at the birth of the child, $N=869140$

\begin{tabular}{|c|c|c|c|c|c|}
\hline \multirow[b]{2}{*}{ Characteristic } & \multicolumn{5}{|c|}{ Maternal depression } \\
\hline & No & $\begin{array}{c}\text { Recent } \\
(0-6 \text { months })^{a}\end{array}$ & $\begin{array}{c}\text { Previous }^{\mathrm{b}} \\
\text { (6-60 months })^{\mathrm{a}}\end{array}$ & $\begin{array}{l}\text { Past } \\
(>60 \text { months })^{a}\end{array}$ & Total \\
\hline Children, $n(\%)$ & 790392 (90.9) & $5219(0.6)$ & $44888(5.2)$ & 28641 (3.3) & 869140 (100.0) \\
\hline \multicolumn{6}{|l|}{ Year of birth, $n(\%)$} \\
\hline $2000-2004$ & 272570 (34.5) & $1413(27.1)$ & 8485 (18.9) & 3133 (10.9) & 285601 (32.9) \\
\hline 2005-2008 & $232152(29.4)$ & $1572(30.1)$ & $13371(29.8)$ & $7221(25.2)$ & 254316 (29.3) \\
\hline $2009-2013$ & $285670(36.1)$ & 2234 (42.8) & 23032 (51.3) & 18287 (63.8) & 329223 (37.9) \\
\hline Mean age of mother, years (SD) & $30.6(4.8)$ & $30.1(5.2)$ & $30.4(5.3)$ & $32.1(4.7)$ & $30.6(4.9)$ \\
\hline \multicolumn{6}{|l|}{ Maternal education, years, $n(\%)$} \\
\hline 10 & $129691(16.4)$ & $1474(28.2)$ & $13383(29.8)$ & $5729(20.0)$ & $150277(17.3)$ \\
\hline $11-15$ & 349177 (44.2) & $2265(43.4)$ & $19294(43.0)$ & 12095 (42.2) & 382831 (44.0) \\
\hline$>15$ & 282547 (35.7) & 1319 (25.3) & $11409(25.4)$ & 10599 (37.0) & 305874 (35.2) \\
\hline Unknown & 28977 (3.7) & $161(3.1)$ & 802 (1.8) & $218(0.8)$ & $30158(3.5)$ \\
\hline \multicolumn{6}{|l|}{ Maternal income, $n[\%]$} \\
\hline Low & $74354(9.4)$ & 433 (8.3) & $3691(8.2)$ & $1506(5.3)$ & 79984 (9.2) \\
\hline Moderate & $464166(58.7)$ & $3680(70.5)$ & $32270(71.9)$ & $18232(63.7)$ & $518348(59.6)$ \\
\hline High & 251783 (31.9) & $1098(21.0)$ & $8927(19.9)$ & $8903(31.1)$ & 270711 (31.1) \\
\hline Unknown & $89(0.0)$ & $8(0.2)$ & $0(0.0)$ & $0(0.0)$ & $97(0.0)$ \\
\hline \multicolumn{6}{|l|}{ Civil status, $n[\%]$} \\
\hline Widowed & $740(0.1)$ & $0(0.0)$ & $81(0.2)$ & $40(0.1)$ & $861(0.1)$ \\
\hline Divorced & $26867(3.4)$ & $311(6.0)$ & $3020(6.7)$ & $1731(6.0)$ & 31929 (3.7) \\
\hline Married & $426805(54.0)$ & 2546 (48.8) & $19049(42.4)$ & $13802(48.2)$ & $462202(53.2)$ \\
\hline Unmarried & 332019 (42.0) & $2349(45.0)$ & $22710(50.6)$ & $13049(45.6)$ & $370127(42.6)$ \\
\hline Unknown & $3961(0.5)$ & $13(0.2)$ & $28(0.1)$ & $19(0.1)$ & $4021(0.5)$ \\
\hline \multicolumn{6}{|c|}{ Maternal mental comorbidities, ${ }^{c} n(\%)$} \\
\hline Yes & 2438 (0.3) & $141(2.7)$ & $1999(4.5)$ & $1332(4.7)$ & $5910(0.7)$ \\
\hline \multicolumn{6}{|c|}{ Paternal mental comorbidities, ${ }^{c} n(\%)$} \\
\hline Yes & $4213(0.5)$ & $78(1.5)$ & $716(1.6)$ & $311(1.1)$ & $5318(0.6)$ \\
\hline \multicolumn{6}{|l|}{ Paternal depression, ${ }^{d} n(\%)$} \\
\hline Non-depressed & 752732 (95.2) & 4624 (88.6) & $39309(87.6)$ & 25736 (89.9) & $822401(94.6)$ \\
\hline Recent & $3285(0.4)$ & $87(1.7)$ & $486(1.1)$ & $210(0.7)$ & $4068(0.5)$ \\
\hline Previous & $14543(1.8)$ & $231(4.4)$ & $2081(4.6)$ & 908 (3.2) & $17763(2.0)$ \\
\hline Past & $19832(2.5)$ & $277(5.3)$ & $3012(6.7)$ & $1787(6.2)$ & $24908(2.9)$ \\
\hline \multicolumn{6}{|l|}{ Preterm birth, $n(\%)$} \\
\hline Yes & $49266(6.2)$ & 433 (8.3) & 3735 (8.3) & $2132(7.4)$ & $55566(6.4)$ \\
\hline No & 739523 (93.6) & 4786 (91.7) & 41087 (91.5) & $26462(92.4)$ & 811858 (93.4) \\
\hline Unknown & $1603(0.2)$ & $0(0.0)$ & $66(0.01)$ & $47(0.2)$ & $1716(0.2)$ \\
\hline \multicolumn{6}{|l|}{ Sex of child, $n[\%]$} \\
\hline Boy & 405161 (51.3) & 2716 (52.0) & $23159(51.6)$ & $14655(51.2)$ & 445691 (51.3) \\
\hline Girl & 385231 (48.7) & $2503(48.0)$ & $21729(48.4)$ & 13986 (48.8) & 423449 (48.7) \\
\hline \multicolumn{6}{|l|}{ Parity, $n(\%)$} \\
\hline 1 & 350203 (44.3) & 2237 (42.9) & $20658(46.0)$ & $11955(41.7)$ & $385053(44.3)$ \\
\hline 2 & 296549 (37.5) & 1985 (38.0) & 14832 (33.0) & 11007 (38.4) & 324373 (37.3) \\
\hline 3 & $107697(13.6)$ & 694 (13.3) & $6533(14.6)$ & $4050(14.1)$ & 118974 (13.7) \\
\hline$\geq 4$ & $35943(4.5)$ & 303 (5.8) & $2865(6.4)$ & $1629(5.7)$ & $40740(4.7)$ \\
\hline
\end{tabular}

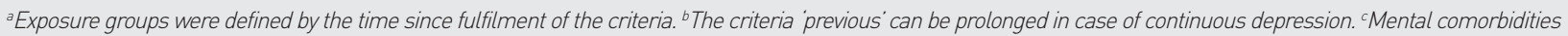

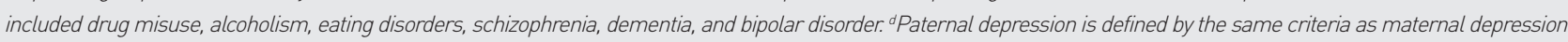
$S D=$ standard deviation. Unknown = missing data.

per child during the first 6 years of life. Hence, $16 \%$ more contacts corresponded to 6.1 contacts. A higher number of contacts were also found for children of mothers with previous depression, $I R R=1.13$, $95 \% \mathrm{Cl}=1.13$ to 1.14 , and past depression, $\mathrm{IRR}=1.15,95 \% \mathrm{Cl}=1.14$ to 1.16 .
Maternal depression was associated with a higher use of supplementary services in the children across all exposure groups and with more positive infection-related test results compared with unexposed children (Table 2). For example, children of mothers with recent depression had $24 \%$ more CRP 


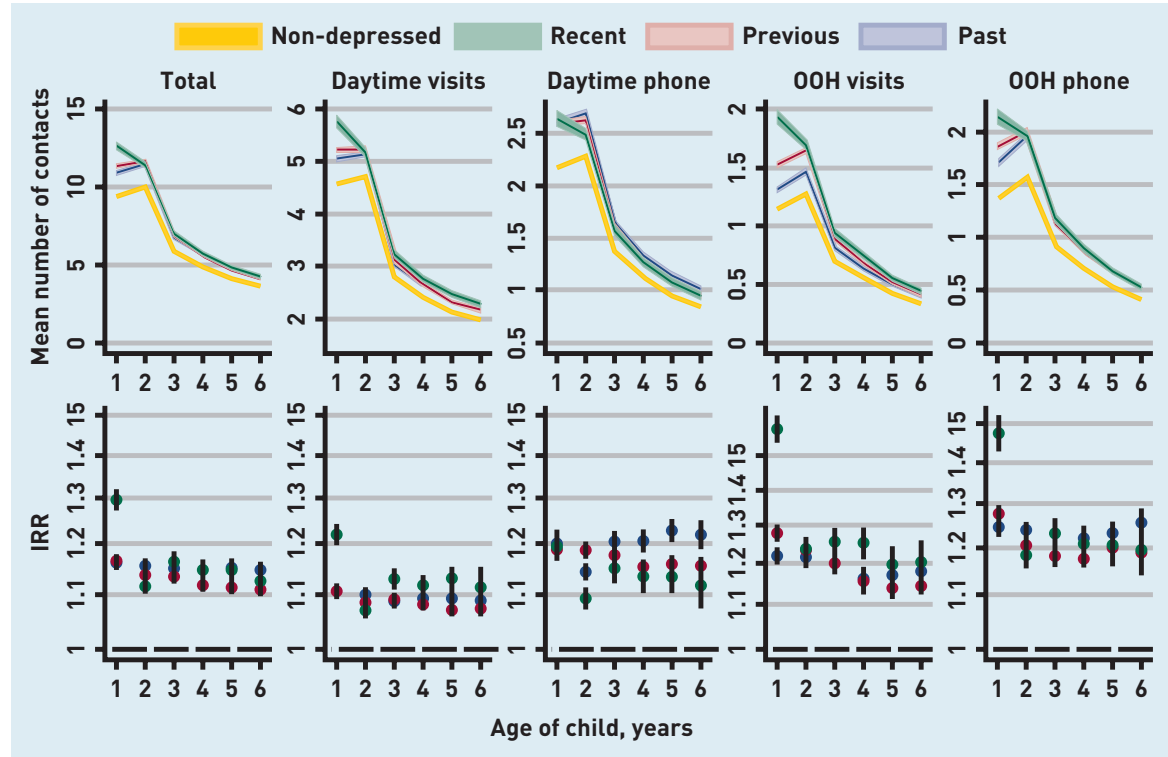

Figure 1. GP utilisation by exposure to maternal depression. Top figures display crude mean number of annual contacts for all four depression categories stratified by child age. Bottom figures display adjusted incidence rate ratios (IRRs) for the three depression categories. Reference group is non-depressed mothers All adjusted for parity (indicator capped at 4), sex of child, gestational age (three groups), maternal age at birth, child age, calendar year, maternal income (three groups), education level (three groups), cohabitation (four groups), paternal depression (four groups), paternal and maternal mental comorbidities (dichotomous). $\mathrm{OOH}=$ out of hours. tests performed than unexposed children. Exposed children also had $21 \%$ more positive CRP test results, which indicated that exposed children were ill more often (Table 2).

Existing research in the same population has revealed that children exposed to maternal depression generally miss more routine childcare visits than their unexposed counterparts. ${ }^{36}$ When stratifying the results on compliance to routine childcare, minimal differences in the association between
Table 2. Adjusted incidence rate ratios and $95 \%$ Cls for contacts with GP and services provided during the child's first 6 years of life

\begin{tabular}{|c|c|c|c|}
\hline Outcome & $\begin{array}{c}\text { IRR (95\% CI) } \\
\text { Recent depression }\end{array}$ & $\begin{array}{c}\text { IRR ( } 95 \% \mathrm{CI}) \\
\text { Previous depression }\end{array}$ & $\begin{array}{c}\text { IRR (95\% CI) } \\
\text { Past depression }\end{array}$ \\
\hline \multicolumn{4}{|l|}{ Contacts } \\
\hline Total & 1.16 (1.15 to 1.17$)$ & $1.13(1.13$ to 1.14$)$ & $1.15(1.14$ to 1.16$)$ \\
\hline Daytime visits & 1.13 (1.12 to 1.13$)$ & 1.09 (1.08 to 1.09$)$ & $1.10(1.09$ to 1.10$)$ \\
\hline Daytime telephone consultations & 1.13 (1.12 to 1.15$)$ & 1.16 (1.15 to 1.17$)$ & 1.20 (1.19 to 1.22$)$ \\
\hline Email consultations & 1.05 (0.98 to 1.13 ) & $1.17(1.12$ to 1.22$)$ & $1.24(1.18$ to 1.31$)$ \\
\hline Out-of-hours $(\mathrm{OOH})$ visits & $1.29(1.28$ to 1.31$)$ & $1.20(1.19$ to 1.21$)$ & $1.20(1.18$ to 1.21$)$ \\
\hline $\mathrm{OOH}$ telephone consultations & 1.25 (1.23 to 1.27$)$ & 1.21 (1.20 to 1.22$)$ & $1.24(1.22$ to 1.25$)$ \\
\hline \multicolumn{4}{|l|}{ Supplementary services } \\
\hline Spirometry & 1.30 (1.09 to 1.55$)$ & $1.21(1.13$ to 1.31$)$ & 1.29 (1.16 to 1.43$)$ \\
\hline Tympanometry & 1.09 (1.05 to 1.12$)$ & 1.02 (1.01 to 1.04$)$ & $1.07(1.05$ to 1.09$)$ \\
\hline C-reactive protein & 1.24 (1.20 to 1.28$)$ & 1.16 (1.14 to 1.19$)$ & $1.18(1.15$ to 1.21$)$ \\
\hline Positive $^{\mathrm{a}}$ & 1.21 (1.13 to 1.29$)$ & 1.15 (1.11 to 1.19$)$ & $1.16(1.11$ to 1.21$)$ \\
\hline Strep A test & $1.19(1.17$ to 1.21$)$ & 1.10 (1.09 to 1.12 ) & 1.11 (1.09 to 1.13 ) \\
\hline Positive Strep $A^{a}$ & 1.19 (1.15 to 1.23$)$ & 1.09 (1.07 to 1.10$)$ & 1.10 (1.08 to 1.13$)$ \\
\hline Urinary stix & $1.21(1.16$ to 1.26$)$ & $1.18(1.15$ to 1.20$)$ & 1.22 (1.18 to 1.25$)$ \\
\hline Positive U-stix ${ }^{a}$ & 1.24 (1.13 to 1.35$)$ & $1.16(1.12$ to 1.21$)$ & $1.17[1.11$ to 1.24$]$ \\
\hline
\end{tabular}

${ }^{a}$ A test was defined as positive if followed by reimbursement of antibiotics (ACT code J01) within a week of the performed test. ${ }^{b}$ Urinary stix is used as a part of the diagnosis of urinary tract infections. $C l=$ confidence interval. $I R R=$ adjusted incidence rate ratio. Adjusted IRRs aggregated by age 0-6 years; adjusted for parity lindicator capped at 4); sex of child, gestational age (three groups); maternal age at birth; age of child; calendar year; maternal income (three groups); education level (three groups); cohabitation (four groups); paternal depression (four groups), paternal and maternal mental comorbidities (dichotomous). The reference group for the adjusted IRRs was children of mothers with no depression. maternal depression and contacts to the GP were found. In children who followed routine childcare visits, the researchers found that children of mothers with depression had 19\% more contacts than unexposed children, $I R R=1.19,95 \% \mathrm{Cl}=1.18$ to 1.20 .

For children who did not follow routine childcare visits, exposed children had 16\% more contacts with the GP compared with unexposed $\mathrm{IRR}=1.16,95 \% \mathrm{Cl}=1.14$ to 1.17 (data not shown). Regression analysis only including children born in the period 2000 to 2007 did not differ from the study's main results (data not shown).

\section{DISCUSSION}

\section{Summary}

This study reveals a greater use of primary health care for children of mothers with depression. Surprisingly, children of a mother who had been depressed $>5$ years ago still had a higher use of health care, which indicates a long-term effect of depression. Children of mothers with recent depression had the highest excess use of all investigated GP services. An increase in the number of contacts to the GP is, however, not necessarily negative. The GP might schedule extra contacts for vulnerable children. Nevertheless, the present results reveal that the difference in visits is especially pronounced in out-ofhours care. This could indicate a higher rate of acute illness in the exposed children or altered health-seeking behaviour in these families. Parenting requires the ability to perceive and interpret the severity of signs and symptoms of disease in the child. Depression is characterised by a loss of energy, depressed mood, self-loathing, feelings of guilt or hopelessness, and cognitive dysfunctions. ${ }^{38}$ Consequently, mothers with depression could be more inclined to fear serious illnesses that cannot wait until the GP is available, or they could have difficulties interpreting symptoms in the child and may thus contact out-ofhours care for guidance.

The present study found a greater use of supplementary services and a higher rate of positive tests in the exposed children. This could be interpreted as a higher rate of infectious disease. If more tests were performed because the GP was influenced by an anxious mother, the researchers would have expected the IRR of positive tests to be lower than the IRR of having the test. Because the IRRs are similar, the tests can be assumed to be prompted by relevant clinical suspicion of infectious illness, and a higher rate of acute illness is thus seen in exposed children. 


\section{Strengths and limitations}

The register-based study is based on an entire birth cohort in Denmark, which ensures powerful statistical analyses and no loss to follow-up. In Denmark, all services in primary care are free of charge, which limits the risk of selection bias. An additional strength is that the Danish registers are considered valid in terms of completeness and registration processes. ${ }^{28,31}$

A limitation in the present study could be the narrow definition of this study's exposure criteria based on contact to a healthcare professional. Children of mothers with nonpharmacologically treated depression would be in the reference group, which might result in an underestimation of the findings. The measures of contacts to GPs are considered valid as the remuneration of GPs is based on the data reported to the National Health Insurance Service Register. ${ }^{32}$ These reports are monitored by the state.

Adjustments constitute the major potential confounders. The researchers had no information on social support and genetic inheritance, though it could have been relevant to adjust for these. Other relevant potential confounders could be poverty, general deprivation, poor nutrition, and school attendance. This information was not available in the present study. However some of the effect of these confounders could be embedded in the included socioeconomic covariates. Additionally, $>90 \%$ of Danish children are in daycare/nursery/nursery school, hence, confounding from this is not expected to explain the present findings. ${ }^{39}$

Most adjustments were performed dynamically to obtain as precise results as possible. As past depression as an exposure category was included, it was not possible to make adjustments for this before exposure. This may have made results from this study vulnerable because some of the covariates could have acted as intermediates.

\section{Comparison with existing literature}

Three large-scale studies on this topic were identified. ${ }^{15,20,23}$ In line with the present study, Sills et al performed a large-scale retrospective matched cohort study in 2007. They reported fewer childcare visits and more sick/emergency visits for all age groups of children (0-17 years) with at least one parent with depression compared with children of non-depressed parents. ${ }^{20}$ This agrees with the present finding of more out-of-hours contacts. Farr et al found a slightly higher risk of hospitalisation and more sick/emergency visits during the first year of life in children of mothers with depression, ${ }^{23}$ especially in children exposed to postpartum maternal depression. Farr et al also reported a higher number of sick visits due to common health problems, for example, upper respiratory infection, otitis media, other infections, other respiratory conditions, worried well, and injury. Results from the present study support this aspect, as a higher use of supplementary services in exposed children was found.

Small-scale studies have found a triple risk of depression in mothers of infants seen by their GP more than three times during the first year of life $e^{19}$ and a triple risk of hospitalisation in infants of mothers with depression. ${ }^{22}$ Other studies have found an association between exposure to maternal depression and increased risk of gastrointestinal infection, respiratory tract infections, and asthma. ${ }^{14-18,40}$ Only one study found no association between maternal depression and healthcare use. ${ }^{24}$ However, this study was limited by its size and the measurement of healthcare use by selfreporting questionnaires with recall periods of up to 12 months.

To explain the reported association between maternal depression during pregnancyand wheezing or rhinitis in infants, Cheng et al suggested that an alteration of the hypothalamic pituitary adrenocortical (HPA) axis caused by epigenetic changes or transfer of glucocorticoids across the placenta may play a role. ${ }^{16}$ Females with depression during pregnancy have been found to have a higher level of hair cortisol. ${ }^{41}$ Children of mothers with postnatal depression have also been found to have higher cortisol levels, which is consistent with HPA reactivity to stress. ${ }^{42}$ An older but very interesting study found that high psychological distress was associated with increased risk of acute infectious illness in a dose-response relationship las psychological distress increases so does the risk of infectious illness) even after adjustments for a variety of key factors. ${ }^{43}$ The offspring exposed to maternal depression may have experienced prolonged emotional and/or epigenetic distress, which could have impaired their resistance to infection.

\section{Implications for practice}

GPs in Denmark are trained in safety netting. This means that the patient is encouraged to contact a doctor if in doubt about the development of a condition. From this point of view, the higher use of health care for children of mothers with depression cannot be interpreted as solely negative. Still, outof-hours care is generally burdened by suboptimal contacts, some without medical relevance. ${ }^{44,45}$ 
The indications that these children are in fact more frequently ill require political attention to ensure early identification and treatment of females at risk. From the GP's perspective, these results may serve as an incitement to enhance the treatment of mothers with depression with a view to improving the offspring's welfare. Support should also be offered to mothers with a history of depression, regardless of the time of the depression.
A previous study has revealed promising results from an intervention targeting pregnant females with depression, anxiety, or stress. ${ }^{46}$ Mindfulness interventions were found feasible and resulted in improvement in both anxiety and depressive symptoms. More availability of treatments, such as mindfulness, may also help to alleviate the increase in demand for healthcare services in primary care.

\section{Funding}

This study was supported by an unrestricted grant from the Lundbeck Foundation (grant number: R155-2012-11280) and by the Program for Clinical Research Infrastructure (PROCRIN), which was established by the Lundbeck Foundation and the Novo Nordisk Foundation, and is administered by Danish Regions. The grant providers had no influence on the study.

\section{Ethical approval}

This study was approved by the Danish Data Protection Agency. According to Danish law, the study did not require approval from the Committee on Health Research Ethics of the Central Denmark Region as no biomedical intervention was performed. The data that support the findings of this study are stored and maintained electronically at Statistics Denmark and are not publicly available.

\section{Provenance}

Freely submitted; externally peer reviewed.

\section{Competing interests}

The authors have declared no competing interests.

\section{Discuss this article}

Contribute and read comments about this article: bjgp.org/letters 


\section{REFERENCES}

1. World Federation for Mental Health. Depression: a global crisis: World Mental Health Day, October 10, 2012. 2012. http://www.who.int/mental_health/ management/depression/wfmh_paper_depression_wmhd_2012.pdf laccessed 14 Nov 2018).

2. Weissman MM, Bland RC, Canino GJ, et al. Cross-national epidemiology of major depression and bipolar disorder. JAMA 1996; 276(4): 293-299.

3. Borg V, Nexø MA, Colt IV, Anderson PF. White paper on mental health, sickness absence and return to work. Copenhagen: National Research Center for the Working Environtment, 2010.

4. Kessler RC, Berglund P, Demler O, et al. The epidemiology of major depressive disorder: results from the National Comorbidity Survey Replication (NCS-R). JAMA 2003; 289(23): 3095-3105.

5. Angst J, Gamma A, Gastpar M, et al. Gender differences in depression. Epidemiological findings from the European DEPRES I and II studies. Eur Arch Psychiatry Clin Neurosci 2002; 252(5): 201-209.

6. Munk-Olsen T, Laursen TM, Pedersen CB, et al. New parents and mental disorders. JAMA 2006; 296(21): 2582

7. Munk-Olsen T, Agerbo E. Does childbirth cause psychiatric disorders? A population-based study paralleling a natural experiment. Epidemiology 2015; 26(1): 79-84.

8. O'Hara MW, Wisner KL. Perinatal mental illness: definition, description and aetiology. Best Pract Res Clin Obstet Gynaecol 2014; 28(1): 3-12.

9. Milgrom J, Gemmill AW, Bilszta JL, et al. Antenatal risk factors for postnatal depression: a large prospective study. J Affect Disord 2008; 108(1-2): 147-157.

10. Campbell SB, Brownell CA, Hungerford A, et al. The course of maternal depressive symptoms and maternal sensitivity as predictors of attachment security at 36 months. Dev Psychopathol 2004; 16(2): 231-252.

11. Matijasevich A, Murray J, Cooper PJ, et al. Trajectories of maternal depression and offspring psychopathology at 6 years: 2004 Pelotas cohort study. J Affect Disord 2015; 174: 424-431.

12. Santos IS, Matijasevich A, Barros AJD, Barros FC. Antenatal and postnatal maternal mood symptoms and psychiatric disorders in pre-school children from the 2004 Pelotas Birth Cohort. J Affect Disord 2014; 164: 112-117.

13. Tompson MC, Pierre CB, Dingman Boger $\mathrm{K}$, et al. Maternal depression, maternal expressed emotion, and youth psychopathology. J Abnorm Child Psychol 2010; 38(1): 105-117.

14. Medsker BH, Brew BK, Forno E, et al. Maternal depressive symptoms, maternal asthma, and asthma in school-aged children. Ann Allergy Asthma Immunol 2017; 118(1): 55-60.

15. Ban L, Gibson JE, West J, Tata LJ. Association between perinatal depression in mothers and the risk of childhood infections in offspring: a population-based cohort study. BMC Public Health 2010; 10(1): 799.

16. Cheng TS, Chen $\mathrm{H}$, Lee T, et al. An independent association of prenatal depression with wheezing and anxiety with rhinitis in infancy. Pediatr Allergy Immunol 2015: 26(8): 765-771.

17. Guo N, Bindt C, Te Bonle M, et al. Association of antepartum and postpartum depression in Ghanaian and Ivorian women with febrile illness in their offspring a prospective birth cohort study. Am J Epidemiol 2013; 178(9): 1394-1402.

18. Rahman A, Bunn J, Lovel H, Creed F. Maternal depression increases infant risk of diarrhoeal illness: a cohort study. Arch Dis Child 2007; 92(1): 24-28.

19. Chee CYI, Chong Y-S, Ng TP, et al. The association between materna depression and frequent non-routine visits to the infant's doctor - a cohort study. J Affect Disord 2008; 107(1-3): 247-253.

20. Sills MR, Shetterly S, Xu S, et al. Association between parental depression and children's health care use. Pediatrics 2007; 119(4): e829-e836.

21. Ververs TF, van Wensen K, Freund MW, et al. Association between antidepressant drug use during pregnancy and child healthcare utilisation. BJOG 2009; 116(12): 1568-1577.

22. Chung EK, McCollumKF, Elo IT, et al. Maternal depressive symptoms and infant health practices among low-income women. Pediatrics 2004; 113(6): e523-e529

23. Farr SL, Dietz PM, Rizzo JH, et al. Health care utilisation in the first year of life among infants of mothers with perinatal depression or anxiety. Paediatr Perinat Epidemiol 2013; 27(1): 81-88.

24. Anderson LN, Campbell MK, daSilva O, et al. Effect of maternal depression and anxiety on use of health services for infants. Can Fam Physician 2008; 54(12): 1718-1719

25. Pedersen KM, Andersen JS, Søndergaard J. General practice and primary health care in Denmark. J Am Board Fam Med. 2012; 25(Suppl 1): S34-S38.

26. Bijl R V, Ravelli A. Psychiatric morbidity, service use, and need for care in the general population: results of the Netherlands Mental Health Survey and Incidence Study. Am J Public Health 2000; 90(4): 602-607.

27. Thygesen CL, Ersbøll KA. Danish population-based registers for public health and health-related welfare research: introduction to the supplement. Scand J Public Health 2011; 39: 8-10.

28. Pedersen BC. Danish civil registration system. Scand J Public Health 2011; 39 22-25.

29. Kildemoes HW, Sørensen HT, Hallas J. Danish National Prescription Registry. Scand J Public Health 2011; 39: 38-41.

30. Thygesen LC, Daasnes C, Thaulow I, Brønnum-Hansen H. Introduction to Danish (nationwide) registers on health and social issues: structure, access, legislation, and archiving. Scand J Public Health 2011; 39: 12-16.

31. Mors O, Perto GP, Mortensen PB. Danish Psychiatric Central Research Register. Scand J Public Health 2011; 39: 54-57.

32. Andersen JS, Olivarius Nde F, Krasnik A. The Danish National Health Service Register. Scand J Public Health 2011; 39(7 Suppl): 34-37.

33. Orlovska $\mathrm{S}$, Vestergaard $\mathrm{CH}$, Bech $\mathrm{BH}$, et al. Association of streptococcal throat infection with mental disorders. JAMA Psychiatry 2017; 74(7): 740-746.

34. Statistics Denmark. Find statistics. https://uww.dst.dk/en/Statistik laccessed 22 Nov 2018).

35. Prior A Fenger-Grøn M, Larsen KK et al. The association between perceived stress and mortality among people with multimorbidity: a prospective population-based cohort study. Am J Epidemiol 2016; 184(3): 199-210.

36. Henriksen DP, Rasmussen L, Hansen MR, et al. Comparison of the five Danish regions regarding demographic characteristics, healthcare utilization, and medication use - a descriptive cross-sectional study. PLoS One 2015; 10(10): e0140197.

37. Lyngsøe BK, Vestergaard CH, Rytter D, et al. Attendance of routine childcare visits in primary care for children of mothers with depression: a nationwide population-based cohort study. Br J Gen Pract 2018; DOI: https://doi. org/10.3399/bjgp18X694565

38. Bentley SM, Pagalilauan GL, Simpson SA. Major depression. Med Clin North Am 2014; 98(5): 981-1005.

39. Møller B. Childcare etc. 2013 living conditions. More children are being looked after. (In Dutch). Denmark Statistics, 2013. https://www.dst.dk/pukora/epub/ Nyt/2014/NR146.pdf (accessed 7 Dec 2018).

40. Giallo R, Bahreinian S, Brown S, et al. Maternal depressive symptoms across early childhood and asthma in school children: findings from a longitudinal Australian population based study. PLoS One 2015; 10(3): e0121459.

41. Caparros-Gonzalez RA, Romero-Gonzalez B, Strivens-Vilchez H, et al. Hair cortisol levels, psychological stress and psychopathological symptoms as predictors of postpartum depression. PLoS One 2017; 12(8): e0182817.

42. Barry TJ, Murray L, Fearon RMP, et al. Maternal postnatal depression predicts altered offspring biological stress reactivity in adulthood. Psychoneuroendocrinology 2015; 52: 251-260.

43. Cohen S, Tyrrell DAJ, Smith AP. Psychological stress and susceptibility to the common cold. N Engl J Med 1991; 325(9): 606-612.

44. Leutgeb R, Walker N, Remmen R, et al. On a European collaboration to identify organizational models, potential shortcomings and improvement options in outof-hours primary health care. Eur J Gen Pract 2014; 20(3): 233-237.

45. Nørøxe KB, Huibers L, Moth G, Vedsted P. Medical appropriateness of adult calls to Danish out-of-hours primary care: a questionnaire-based survey. BMC Fam Pract 2017; 18(1): 34

46. Woolhouse H, Mercuri K, Judd F, Brown SJ. Antenatal mindfulness intervention to reduce depression, anxiety and stress: a pilot randomised controlled trial of the MindBabyBody program in an Australian tertiary maternity hospital. BMC Pregnancy Childbirth 2014; 14: 369 